\title{
Regulation and Innovation: Approaching Market Failure from Both Sides
}

\author{
Yafit Lev-Aretz ${ }^{\dagger} \&$ Katherine J. Strandburg ${ }^{t \dagger}$
}

Regulation is often claimed to be the enemy of socially desirable innovation because of factors including innovation's unpredictability and regulation's compliance costs. In this essay, we bring two intellectual property scholars' perspectives to bear on the question of regulation's impact on innovation. We offer a novel, yet intuitive, analytical framework that takes both market demand failures, and failures of supplier appropriability into account. Traditionally, regulation seeks to mitigate market failures that create deviations between the demand portfolio perceived by suppliers and the socially optimal demand portfolio. Studies of the interplay between regulation and innovation have mostly taken this perspective, considering the impact of various regulatory transaction and compliance costs on innovation. Intellectual property law and competition law target a different sort of problem, where markets fail to supply products and services at competitive prices or to undertake innovative activities because of supplier appropriability issues.

We argue that these demand-misalignments and appropriability failures, though analytically distinct and commonly treated separately, work in parallel to determine the extent to which the market's portfolio of innovative activity is socially suboptimal. Discussing the relationship between regulation and innovation in terms of demand misalignment, appropriability failures, and the mutual influence they bear on each other, opens up a new way of understanding this long debate. Our analysis shows the futility of sweeping generalizations about the relationship between regulation and innovation and highlights the crucial role of regulatory design.

\footnotetext{
${ }^{\dagger}$ Assistant Professor of Law, Zicklin School of Business, City University of New York. This Article was co-authored during Professor Lev-Aretz's Post-Doctoral Fellowship at the Information Law Institute (ILI) at New York University School of Law. ILI Fellowships are funded in part by a generous grant from Microsoft Corporation.

${ }^{\dagger}$ Alfred B. Engelberg Professor of Law and Faculty Director, Information Law Institute, New York University School of Law. Professor Strandburg acknowledges the generous support of the Filomen D. Agostino and Max E. Greenberg Research Fund. The authors are also grateful for the terrific research assistance from Grace Ha, Melissa Arseniuk, Christopher Bettwy, Gabriel Ferrante, Melodi Dincer, and Sara Spaur, and for the helpful comments from members of the NYU Privacy Research Group and Information Law Institute, attendees at the Privacy Law Scholars Conference 2017, NYU faculty workshop attendees, and New York Law School faculty workshop attendees.
} 


\section{Introduction}

From pharmaceuticals ${ }^{1}$ and environmental markets ${ }^{2}$ to DNA testing ${ }^{3}$ and big tech ${ }^{4}$ the argument that regulation can "stifle" innovation has a long pedigree. Simply put, regulation is said to inhibit innovation by limiting potentially innovative paths and/or increasing innovation costs. As we claim in this Essay, however, the current popular debate around the interplay between regulation and innovation has suffered from much oversimplification. We hope to offer some careful unpacking to understand the relationship between regulation and innovation in broader, yet contextualized, terms.

To do this, we must first step back to consider the goals of classical regulation on the one hand, and of intellectual property (and to some extent competition law) on the other hand. The social benefits ascribed to competitive markets result from the assumption that consumer demand will induce suppliers to produce a socially beneficial portfolio of goods and services at competitive prices. ${ }^{5}$ The same assumptions underlie our reliance on markets to induce socially valuable innovation, since investments in innovation also are premised on perceptions of consumer demand. ${ }^{6}$ Of course, these assumptions sometimes fail. Through regulation, intellectual property law and competition law aim to address such failures. In this Essay, we explore the interplay between regulation and innovation by bringing traditional regulation together with intellectual property and competition law. In doing so, we clarify the interplay between them and add nuance to the currently oversimplified regulationinnovation debate.

Specifically, we do so by making an intuitive, yet underexplored, conceptual differentiation: regulation addresses misaligned market demand signals on the demand-side, while intellectual property and competition laws mitigate "failures of appropriability" on the supply-side. Misaligned market demand signals arise, for example, from externalities or information asymmetries and are the classic justifications for regulation. Traditionally, regulation in areas such as health and safety or environ-

1 Richard Allen Epstein, Overdose: How Excessive Government Regulation STIFLES PHARMACEUTICAL INNOVATION (2006).

${ }^{2}$ Susse Georg, Regulating the Environment: Changing from Constraint to Gentle Coercion, 3 BUS. STRATEGY \& THE ENV'T, Jan. 1994, at 11-20.

3 Derek Khanna, Regulations Stifle Innovation, THE HiLl (Sept. 15, 2015), https:/thehill.com/blogs/congress-blog/technology/253625-regulations-stifle-innovation [https://perma.cc/JK3E-D7BV].

${ }^{4}$ Tom Relihan, Will Regulating Big Tech Stifle Innovation?, MIT IDEAS MADE TO MATTER (Sept. 27, 2018) https://mitsloan.mit.edu/ideas-made-to-matter/will-regulating-big-tech-stifleinnovation [https://perma.cc/Q3SD-EUSV].

${ }^{5}$ See Kenneth G. Elzinga, The Goals of Antitrust: Other than Competition and Efficiency, What Else Counts?, 125 U. PA. L. REV 1191, 1194 (1977).

${ }^{6}$ See David J. Teece, Business Models, Business Strategy and Innovation, 43 LONG RANGE PLAN. 172, 176 (2010). 
mental protection, seek to mitigate misaligned market demands, which are understood as deviations between the demand portfolio perceived by suppliers and the socially optimal portfolio of demand for goods and services. ${ }^{7}$ Regulation can tackle this problem either by communicating socially preferred demand directly to suppliers or by attempting to realign the consumer demand expressed in the market. Either approach can be implemented using a menu of regulatory tools that includes mandates, incentives, grants, and so forth.

Unlike regulation that tackles demand-side issues, intellectual property law and competition law both target a different sort of problem-one of failed supply. Markets sometimes fail to supply products and services at competitive prices-or to undertake innovative activities-even when suppliers can perfectly perceive consumer demand for them. These failures, which we term "failures of appropriability," are due to either freerider problems or barriers to entry, which have been the focus of innovation policy and intellectual property doctrine.

Free-rider problems arise when innovators, who have invested in new technologies or other creative outputs, are threatened by the possibility that competitors will "freeride" on their efforts. ${ }^{8}$ Because competitors can copy, rather than invest in creative activities, they can afford to offer lower prices. Innovators are then forced to match those prices, which results in them being unable to recoup their creative investments. Anticipating this sequence of events, potential innovators will be deterred from investing in innovative activities. ${ }^{9}$ Intellectual property provides a degree of market exclusivity for a limited period of time to address potential "freeriding" by competitors. ${ }^{10}$

While intellectual property is designed to address potentially higher costs of entry for first entrants, competition law attempts to deal with the opposite concern: higher costs of entry for later entrants. Barriers to entry deter latecomers from competing and capitalizing on follow-on inno-

\footnotetext{
${ }^{7}$ The term "regulation" has both broad and narrow usages. The broad approach groups together all statutory interventions that interfere with or limit market players' behaviors. Some have debated, for example, whether intellectual property should be deemed "regulation" or "property." The narrow approach looks at regulation as addressing failures in market demand. Here we use "regulation" in this narrow sense, which we believe encompasses its most commonly understood meaning. Of course, regulations can be designed in many ways, some of which are sometimes called "demand-side" regulations, because they attempt to shift consumer demand, and others are sometimes called "supply-side" regulations because they target suppliers. Our definition focuses on the source of the problem in scenarios where there is socially sub-optimal perceived demand. As such, the definition is agnostic towards the best approach to regulatory design, which we presume will depend on the specifics of any given scenario.

${ }^{8}$ See Garrett Hardin, The Tragedy of the Commons, 162 SCIENCE 1243, 1246 (1968) (referring to the "free-rider problem" as "the tragedy of the commons").

${ }^{9}$ See Marshall A. Leaffer, Protecting United States Intellectual Property Abroad: Toward a New Multilateralism, 76 IOWA L. REV. 273, 279 (1991).

${ }^{10}$ See, e.g., Richard A. Posner, Antitrust in the New Economy, 68 AnTITRUST L.J. 925, 927 (2001) ("Without legal protection, the creator of intellectual property may be unable to recoup his investment, because competitors can free ride on it.").
} 
vation in a market dominated by incumbents. ${ }^{11}$ Barriers to entry in this context refer to structural economic disadvantages faced by some entrants but not others. ${ }^{12}$ Competition law aims to address barriers to entry of this sort because they are associated with anti-competitive behavior and monopolization. ${ }^{13}$

Our claim is that regulation and intellectual property/competition law, though analytically distinct and commonly treated separately, work in parallel and in combination to determine the extent to which the market's portfolio of innovative activity is socially sub-optimal. Despite this interplay, the regulatory literature, including the literature on regulation and innovation, has paid little attention to "failures of appropriability," 14 effectively assuming that intellectual property law operates independently to resolve them. ${ }^{15}$ We offer a novel paradigm from two intellectual property scholars' perspective to bear on the question of regulation's impact on innovation. Discussing the relationship between regulation and innovation in terms of demand misalignment, appropriability failures, and the mutual influence they bear on each other, opens up a new way of understanding this long debate.

We begin, in Part II, by framing the controversy as presented in the regulation-innovation debate and highlighting weaknesses in current approaches. In Part III, we outline the roles of (i) traditional regulation and (ii) intellectual property and competition law in terms of the market failures they are designed to address. In Part IV we consider the effects of regulation on realigned demand, both directly and in terms of overall reduction in innovation. Finally, in Part V, we bring everything together by looking at the mutual influence of regulation and innovation policy on each other from the perspective of misaligned demand signals and appropriability failures. We close with a conclusion.

\footnotetext{
${ }^{11}$ See generally David L. White, Shaping Antitrust Enforcement: Greater Emphasis on Barriers to Entry, 1989 B.Y.U. L. REV. 823, 823 (1989).

12 See, e.g., R. S. Khemani \& D. M. Shapiro, Barriers to Entry, OECD Glossary of INDUSTRIAL ORGANISATION ECONOMICS AND COMPETITION LAW 13-14 (1990), http://www.oecd.org/regreform/sectors/2376087.pdf [https://perma.cc/N8AL-ST7Y].

${ }^{13}$ Interestingly, the free-rider problem can also be viewed through a barrier-to-entry lens. The free-rider problem occurs because first entrants face higher costs than later entrants. This sort of barrier to first entry is essentially the reverse of the standard barrier to later entry. Both sorts of barriers to entry tip the playing field away from a competitive market in which all potential entrants face similar costs and entry conditions. One advantage of conceptualizing intellectual property law and competition law as responding to tilts in directions away from a level playing field is that it becomes easier to see how free-riding concerns can be canceled out-and even overcorrected for-by barriers to entry for follow-up innovators.

${ }^{14}$ The converse is also true. The IP and innovation policy literature mostly ignores the possibility that market demand for innovative activity might be misaligned with social welfare except in discussions of technology transfer and the relationship between IP and government-funded science.

${ }^{15}$ Puzzlingly, the existing literature on the interplay between regulation and innovation is largely lacking in contributions from intellectual property scholars.
} 


\section{Framing the Regulation-Innovation Debate}

The contention that regulation will stifle innovation is hardly new; it is a trope that surfaces regularly in response to proposals to regulate technology and has provoked a longstanding and politically contentious policy debate. The academic literature on the interplay between regulation and innovation focuses primarily on a few topics, most notably environmental regulation. ${ }^{16}$ Much of this literature is empirical and the outcomes depend to some extent on the methodologies and metrics for innovation that are used. The majority view, to the extent that one exists, is that the net impact of regulation on innovation depends largely on regulatory design, with commentators suggesting a variety of design factors that are likely to affect the outcome. ${ }^{17}$

For example, one of the most extensive strands of empirical literature addressing the relationship between innovation and regulation focuses on the well-known Porter Hypothesis, which claims that "if properly designed, environmental regulations can lead to 'innovation offsets' that will not only improve environmental performance, but also partially - and sometimes more than fully - offset the additional cost of regulation." ${ }^{18}$ Commentators have described the Porter Hypothesis as having strong and weak forms. The weak form asserts that regulation often triggers innovation, especially through means of compliance, ${ }^{19}$ while the strong version asserts that the benefits that accrue to firms from this innovation often offset the costs they bear from regulation..$^{20} \mathrm{~A}$ recent review of empirical studies found consistent support for the weak versionnamely that firms respond to regulation by innovating-but less clarity about the strong version. ${ }^{21}$ While older studies tended to push against the strong version, several more recent studies-some of which took account of dynamic effects and changing market conditions-favored it. ${ }^{22} \mathrm{Im}$ -

${ }^{16}$ E.g., INNOVATION-ORIENTED ENVIRONMENTAL REGULATION: THEORETICAL APPROACHES AND EMPIRICAL ANALYSIS (Jens Hemmelskamp, Klaus Rennings \& Fabio Leone eds., 2000); Adam B. Jaffe \& Karen Palmer, Environmental Regulation and Innovation: A Panel Data Study, 79 REV. ECON. \& STAT. 610 (1997); Wesley A. Magat, The Effects of Environmental Regulation on Innovation, 43 L. \& CONTEMP. PROBS. 4 (1979).

17 See, e.g., Luke A. Stewart, Inst. Med. Comm. on Patient SAfety \& Health IT, The IMPACT OF REGULATION ON INNOVATION IN THE UNITED STATES: A CROSS-INDUSTRY Literature ReVIew, 7-8, 21-23 (2010); Stefan Ambec et al., The Porter Hypothesis at 20: Can Environmental Regulation Enhance Innovation and Competitiveness?, 7 REV. ENVTL. ECON. AND POL'Y 1, 8-10 (2013).

${ }^{18}$ Ambec et al., supra note 17, at 3-4; see also Michael E. Porter \& Claas van der Linde, Toward a New Conception of the Environment-Competitiveness Relationship, 9 J. ECON. PERSP. 97 (1995).

${ }^{19}$ In other words, regulation motivates innovation when businesses and individuals attempt to make compliance feasible, more efficient, and/or less costly.

${ }^{20}$ Ambec et al., supra note 17, at 5.

${ }^{21}$ Ambec et al., supra note 17, at 9-10.

${ }^{22}$ See, e.g., Jung-Ah Hwang \& Yeonbae Kim, Effects of Environmental Regulations on Trade Flow in Manufacturing Sectors: Comparison of Static and Dynamic Effects of Environmental Regulations, 26 Bus. STRATegy \& THE EnV’T 688, 699 (2017); Paul Lanoie, Michel Patry \& 
portantly, the Porter Hypothesis and its tests do not address the net social welfare effects of regulation. Where the strong version of the Porter Hypothesis holds, it is plausible that the regulation is socially beneficial overall (though one could imagine counterexamples). Even if the strong version does not hold, however, a regulation may be justified from a social perspective by creating social benefits to more than offset the compliance costs to firms. ${ }^{23}$

One novel theoretical framework for analyzing the interplay between regulation and innovation builds on Richard Stewart's seminal article from 1981. ${ }^{24}$ Stewart's framework draws a distinction between "market innovation" and "social innovation." The article defines "market innovation" in terms of "new products and processes" that "increase productivity as measured by traditional national income accounting" or "create benefits that firms can capture through the sale of goods and services in the market." 25 "Social innovation" is defined as "product or process innovations that create social benefits, such as cleaner air, that firms cannot directly capture through market sales." ${ }^{.26}$ Stewart argues that regulations may adversely affect "market innovation" by imposing technical constraints, forcing firms to make expenditures to comply, creating ex ante uncertainty as to whether innovations will meet regulatory requirements, and introducing delay associated with determining whether new products and processes meet such requirements. ${ }^{27} \mathrm{He}$ argues that "government, rather than the market, ordinarily must provide incentives for regulated firms to undertake investment necessary to generate social innovation" and critiques command-and-control approaches to regulation for failing to successfully incentivize social innovation. ${ }^{28}$ Stewart's marketsocial innovation framework has been adopted by a number of later scholars. $^{29}$

Though Stewart's distinction between "market innovation" and "social innovation" highlights important aspects of the relationship between innovation and regulation, we think that attempts to actually categorize innovations within this framework or to judge a regulatory scheme in

Richard Lajeunesse, Environmental Regulation and Productivity: Testing the Porter Hypothesis, 30 J. PRODUCTIVITY ANALYSIS 121, 128 (2008).

${ }^{23}$ Innovations that reduce the costs of compliance are generally socially beneficial once a regulation is in place. Of course, it is always possible that a regulation is badly designed, so that the costs of even the most efficient forms of compliance outweigh its benefits. Compliance with welldesigned regulation is socially beneficial, however, even if it creates new costs, because the regulation addresses market failures that are also associated with social costs. As long as the regulation is well-designed, innovations that reduce compliance costs are also socially beneficial.

${ }^{24}$ Richard Stewart, Regulation, Innovation, and Administrative Law: A Conceptual Framework, 69 CALIF. L. REV. 1256 (1981).

${ }^{25} I d$. at 1261.

${ }^{26}$ Id. at 1279.

${ }^{27}$ Id. at 1281.

${ }^{28} I d$.

${ }^{29}$ See, e.g., Tal Z. Zarsky, The Privacy-Innovation Conundrum, 19 LEWIS \& CLARK L. REV. 115, $126(2015)$. 
terms of its production of "social innovation" will be confusing and potentially misleading. As Stewart explicitly recognized, "[a] given innovation may confer both market and social benefits." ${ }^{30}$ This point tends to fall by the wayside in later analyses, but it is crucial because nearly every innovation produced by market actors will have both "market" and "social" benefits.

Barring complete government subsidy, we cannot expect firms-who are creatures of the market, after all-to undertake any innovative activity unless they anticipate at least some market benefits. Thus, firms will never engage in purely "social" innovation. To induce firms to engage in this sort of innovation, a regulation must somehow create capturable benefits, thus transforming the innovation, at least in part, into a market innovation. On the flip side, while some purely market innovations may exist, the standard understanding is that innovation, by its very nature, is likely to create positive externalities or "spillovers." 31 And while intellectual property aims to allow innovators to capture enough returns to cover their costs, intellectual property rights are capped so that downstream innovators (and society) can benefit from any remaining spillovers. The bottom line is that the vast majority of innovations produced by firms will create some benefits captured by firms and some benefits that spill over to society. Classifying them as either "market innovations" or "social innovations" is either impossible or meaningless.

Beyond this, the classification of innovations as "social" because they "create social benefits, such as cleaner air, that firms cannot directly capture through market sales" is inadequate if regulation is to be judged by how much it induces "social innovation" without suppressing "market innovation." The definition is problematic for several reasons. For one, producing "social innovation" is not the only defensible justification for regulation. Stewart's article describes the "basic justification for environmental, health, and safety regulation" as "preventing or reducing harmful spillovers or externalities such as pollution generated by producers and consumers in a market economy," while "social innovation" is essentially defined as innovation that reduces this sort of externality. ${ }^{32}$

Regulations might be justified by other sorts of market failures, especially outside of the environmental arena. Collective action problems can hinder the achievement of positive social goals even when there are no negative externalities to counteract. Perhaps more controversially, in

${ }^{30} I d$. at 1279 .

${ }^{31}$ See, e.g., Brett M. Frischmann \& Mark A. Lemley, Spillovers, 107 ColuM. L. REV. 257, 259 (2007); Zachary Liscow \& Quentin Karpilow, Innovation Snowballing and Climate Law, 95 WASH. U. L. REV. 387, 389-90 (2017). ("Economic analysts agree that, for innovations that could exacerbate or mitigate a social harm, there are two potential reasons for government intervention. First, since society benefits from innovation to a greater extent than innovators themselves capture (partly because not all ideas can be patented), innovators produce positive "externalities" for society.").

${ }^{32}$ Stewart, supra note 24 , at 1263. 
the context of privacy regulation, regulations often aim to correct market failures that are not naturally characterized in terms of externalities of any sort. Consumer protection regulations are often designed to counteract information asymmetries and other problems that lead consumers to purchase goods and services that do not align with their actual preferences. A broader understanding of the sorts of innovation that regulation should induce is required.

Moreover, the goals of regulation can sometimes be met without any sort of social innovation. Some sorts of innovation may be suppressed because of their negative externalities and/or other market failures. As Stewart's framework suggests, regulations often are designed to deal with negative externalities produced by market innovations. While it is certainly a societal bonus if such regulations also incentivize innovations that generate positive externalities, surely such socially positive innovations are not requirements for socially beneficial regulation. We will judge such a regulation primarily in terms of the way that it picks and chooses among market innovations. A possible example from recent news reports is the 3D-printable handgun. We might decide as a society to use regulation to discourage innovations developed to improve the production of 3Dprintable handguns. If we agreed on this goal, what would we consider in evaluating a specific proposal's effects on innovation? We might be concerned about collateral suppression of socially beneficial 3D-printing innovations or socially beneficial innovations in gun design. But the regulation would be unlikely to fail simply because it achieved its goal by suppressing the market innovation associated with 3D-printable gun production or because it failed to produce any additional social innovation.

Finally, the definition of social innovation in terms of benefits that firms cannot capture through market sales blurs the distinction between market failures that result from faulty demand signals, and those that result from "failures of appropriability" due to competition among suppliers. The collective action problem that keeps citizens from pooling their money to pay for the installation of technology to improve air quality creates a misalignment between market demand signals and citizens' true preferences. Intellectual property law deals with an entirely different sort of market failure, one caused by a supplier's fear that his/her investments in developing such a technology will be undercut by market competitors who are spared the upfront investment. ${ }^{33}$

\footnotetext{
${ }^{33}$ This distinction might seem artificial, but it is not; this is the case because markets solve a number of different informational and coordination problems, which include not only "what do consumers want?" but also "who will supply it?" The second question is particularly important for innovation, since it is difficult to predict in advance who will do the best job. There are, of course, non-market mechanisms for handling this issue (for example, peer-reviewed grant funding), but one reason for relying on intellectual property is that inventors identify themselves through their activities and are rewarded after the fact. Thus, while overcoming the demand-side collective action problem to collect the funds needed to pay for the clean air technology allows
} 
In the next Part, we present a framework for analyzing the interplay between regulation and innovation that takes a different approach. Rather than attempt to categorize innovations, we will focus on how the market failures associated with misaligned demand signals and "failures of appropriability" affect the market's ability to induce socially beneficial innovation.

\section{When Demand and Supply Fail}

The argument that regulation can "stifle" innovation is often made generically, with little analysis and in a contextual vacuum. To analyze whether and when to take it seriously, we start by unpacking what it might mean. We step back to consider the economic issues underlying theories of regulation as well as intellectual property and competition law.

The portfolio of innovative activity induced by the market reflects the combined effects of two distinct forces, (i) the market demand signals perceived by potential innovators and (ii) the extent to which those suppliers expect to be able to appropriate market returns from particular innovative activities. ${ }^{34}$ We can describe these forces loosely as "what consumers are willing to pay" and "what suppliers are able to charge." If either of these forces is misaligned, markets will fail to produce socially optimal portfolios of innovative activity. Regulatory policy traditionally focuses on market failures that occur when market demand signals are misaligned with individual or social preferences, while intellectual property doctrine focuses on what we call "failures of appropriability," wherein suppliers are able to charge either too much or too little to induce optimal investment in innovation. ${ }^{35}$

\section{A. Misaligned Market Demand Signals}

Reasons for misalignment between market demand signals and social welfare fall into three categories: (i) externalities and related collective action problems, (ii) failures to accurately express individual preferences because of information asymmetries, irrational behaviors, and/or

consumers to signal their demand, it does not tell them who should get the money. Relying on the competitive market to answer that question brings appropriability questions into play.

${ }^{34}$ There are, of course, other factors that influence the market's portfolio of innovative activities, perhaps most importantly the "state-of-the-art" for a given technology, which affects the cost of innovation. Neither regulation nor intellectual property affects these costs in the short run. In the long run, as recently explored by Liscow and Karpilow, supra note 31, there may be considerable path dependence, given that the spillovers of innovation tend to be most helpful in closely related innovation. This path dependence suggests an additional reason for attempting to align innovation incentives with social benefit.

${ }^{35}$ We also acknowledge that there are various definitions of "demand failure," "demand-side regulation," "supply-side failure," and "supply-side regulation," in the regulatory literatures. We have no quarrel with those usages, but for our purposes, we find it useful to parse things differently. We attempt to define our terms explicitly here to avoid confusion with these other usages. 
transaction costs, and (iii) misalignment with social values such as distributive justice, treatment of minorities, and ethical norms. ${ }^{36}$ We describe each of these categories in more detail below. Here, we take a broad view of market failures and a correspondingly broad view of justifications for regulation. Our general arguments do not rely on that broad approach, however, but require only two minimal assumptions. First, we assume that market demand signals can fail due to a misalignment between (i) true individual and social preferences and (ii) the demand expressed in market transactions. Second, we assume that government regulation can be designed and enacted to mitigate such misalignments. In other words, government regulation is not so hopelessly infected with public choice problems that the cure is inevitably worse than the disease. Normative and empirical debates about particular justifications for regulation would, of course, enter into the detailed contextual analysis that is required to evaluate particular regulatory proposals in light of our analysis. Our broad view of the demand problems that can justify regulation is contestable and becomes more controversial as one goes down the list.

\section{Externalities and Related Collective Action Problems}

Classically, market demand may fail to reflect social preferences because of externalities or collective action problems. These are related, but distinct issues. Externalities arise when those who are not party to an economic transaction are affected by it, either negatively or positively. Regulatory policy focuses on externalities that affect individual consumers. Environmental regulations, for example, classically address negative externality issues, such as when those living in the vicinity of a manufacturing plant are harmed by pollution but have no market channel for expressing their preferences because they are not customers of the plant. When negative externalities are large enough, the market will induce socially undesirable innovations that generate net revenue to businesses because neither they nor their customers internalize the social costs. Conversely, if positive externalities are large enough, the willingness to pay expressed in the market might be insufficient to induce socially desirable innovations.

In principle, consumers affected by externalities might be able to overcome them by cooperating to pay suppliers to take them into account. For example, the neighbors of a polluting factory could pay the factory to install air filters. Regulation commonly targets situations in which such cooperation does not occur or is very wasteful due to high transaction costs, consumer lack of information, strategic behavior (by either consumers or businesses), and so forth. Collective action problems are particularly likely to prevent effective responses to externalities be-

\footnotetext{
${ }^{36}$ These categories are neither entirely distinct nor comprehensive. They are simply illustrative.
} 
cause the affected individuals are ordinarily strangers to one another and to the business creating the externality. When negative externalities affect public goods, such as air quality, collective action problems are heightened by strategic dilemmas, because each individual has an incentive to wait for others to expend the effort required to solve the problem.

\section{Distortions of Individual Preferences}

Consumer purchasing behavior may also fail to reflect actual individual preferences, thus distorting the demand signals the market sends to suppliers. Reasons for such distortion include lack of information, cognitive biases, consumer myopia, and even the declining marginal value of money. Health and safety regulations often respond to this sort of failure. Similarly, consumer protection regulations are often justified in terms of consumers' lack of information and expertise needed to assess the quality of products and services or to evaluate the transaction terms. For example, regulations mandating labeling address this sort of issue, as do certifications or licensing requirements, cooling-off periods, and many more.

Collective action problems can also arise in circumstances that do not involve externalities. They may arise whenever cooperation could reduce the transaction costs or information asymmetries associated with individual transactions. Essentially, this can be the case when the measures needed to contend with these problems are at least partially nonrivalrous. In such cases, the issue does not concern externalities since individuals are not directly affected by other parties' transactions. Instead, the issue is whether the costs can be reduced by spreading them to the collective. In essence, the idea is to kill two transaction cost birds with one stone. ${ }^{37}$ If there is sufficient non-rivalry, cooperation could reduce transaction costs for each consumer enough to allow her to pursue her individual interests. Class action litigation is designed to overcome this sort of collective action problem, by allowing consumers to avoid duplicative costs associated with litigation.

\section{Misalignment with Social and Ethical Values}

Finally, market demand signals might fail to account for important social values such as distributive justice, minority rights, and ethical norms. There are various reasons why markets might fail to account for such values. For one, these values often concern systemic effects that are not visible to individuals when they are transacting. If individuals cannot evaluate the systemic impact of their transactions, their market behaviors

\footnotetext{
${ }^{37}$ What is required is some degree of non-rivalry associated with the transaction costs. For example, certain pieces of information might be useful for many individuals in their discrete transactions with a supplier, even if the information must be deployed separately in each transaction and each individual cares only about the outcome of his/her own transaction.
} 
cannot express the value they place on those effects. For example, an individual consumer who values economic equality highly will find it difficult, if not impossible, to assess the distributive effects of her individual market transactions. The expression of such systemic values is also rife with collective action problems. Apart from these issues, most citizens of constitutional democracies would presumably agree that some questions are appropriately decided by majority vote, rather than by market transactions, and that some rights are not defeasible even by majority vote. A free market for human body parts is illustrative. Trading human body parts has widely been deemed so morally unacceptable and likely to produce negative systemic effects that democracies have generally opted to prohibit it, despite the existence of market demand and contrarian views about its moral and systemic implications. These are the sorts of values we have in mind in this category of justifications for regulation.

\section{B. "Failures of Appropriability": What Suppliers Can Charge}

Realigning demand signals with social preferences is only one side of the story. Markets may fail to deliver the portfolio of goods and services that society demands if suppliers' ability to appropriate market returns varies significantly among goods and services. In such a situation, suppliers will shift production toward goods and services with relatively high appropriability, thus distorting the market's portfolio of goods and services, even if demand signals are perfectly aligned with individual and social preferences. As a general rule, markets rely on competition to keep the appropriability landscape level. That being said, innovators can run into appropriability problems even in competitive markets.

\section{Free Riding and Intellectual Property Protection}

Appropriability failures, in the form of free-rider problems, are the quintessential justification for intellectual property. Free-rider problems arise because innovators often make upfront investments that competitors can avoid by copying. To recoup his/her investment through market return, an innovator needs to charge supra-competitive prices (at least for a while). If competitors can cheaply copy the innovation, however, they can afford to charge competitive prices, thereby freeriding on the innovator's investment. To compete, innovators will be forced to lower their prices to a competitive level, but they may then be unable to recoup their creative investments. Anticipating this free-rider problem, potential innovators may be deterred from investing in innovative activities altogether. When that occurs, the market's portfolio of goods and services is distorted away from innovative activity, even when there is demand for it.

Intellectual property law responds to the free-rider problem by awarding exclusive rights to innovators, allowing them to charge supra- 
competitive prices during the term of intellectual property protection. ${ }^{38}$ By charging supra-competitive prices, innovators can recoup their upfront investments. Moreover, since they can expect intellectual property protection, they will no longer be deterred from innovation that responds to consumer demand. If all goes well, intellectual property protection will level out the appropriability landscape. However, intellectual property exclusivity can create two sorts of social costs. First, it can overcompensate (or undercompensate) innovators if the length and breadth of the exclusive rights are not tailored to the innovator's upfront investment. ${ }^{39}$ Second, exclusivity is a socially costly way to "reimburse" innovators, ${ }^{40}$ because it restricts the innovative activities of follow-on innovators in a way that a simple repayment would not.

Recognizing these dangers, intellectual property doctrine is designed-at least in its aspirations-to avoid awarding unnecessary exclusivity. Patent law's non-obviousness requirement, for example, disqualifies trivial inventions from patent protection. It attempts to limit the awarding of patents only to cases where the natural advantages first movers enjoy when entering a new market would not be sufficient to cover the costs associated with the innovation, such as research and development (R\&D) costs. ${ }^{41}$ Patent law's disclosure requirements, under which a patent application must disclose the invention in sufficient detail for an individual skilled in the art to carry out that invention, strike a balance between awarding current innovators and incentivizing follow-on innovators. ${ }^{42}$ Copyright's fair use doctrine, which protects unauthorized copying of copyrighted works for a limited and "transformative" purpose, similarly limits the effects of exclusivity on downstream creativity. ${ }^{43}$ Trade secrecy exclusivity is limited by permitting reverse engineering and independent invention. ${ }^{44}$

\footnotetext{
${ }^{38}$ See Posner, supra note 10, at 926.

${ }^{39}$ It is commonly said that intellectual property's supra-competitive prices impose socially costly deadweight losses even if they are tailored to the innovator's upfront cost. However, someone presumably has to pay the costs of an innovation. Consumers seem to be the natural choice (though perhaps not only those who buy during the IP term). In any event, we are focusing on overly broad intellectual property exclusivity, which is undoubtedly socially costly.

${ }^{40}$ Assuming that a competitive market, rather than a monopoly, is the best driver of innovation.

${ }^{41}$ The non-obviousness requirement mandates that an invention must be sufficiently different from the previous innovation landscape ("prior art") such that "a person having ordinary skill in the art to which the claimed invention pertains" would not deem it to be obvious. 35 U.S.C. $\S$ 103 (2012) ("A patent . . may not be obtained ... if the differences between the claimed invention and the prior art are such that the claimed invention as a whole would have been obvious before the effective filing date of the claimed invention to a person having ordinary skill in the art to which the claimed invention pertains.") (emphasis added).

${ }^{42}$ Jason Rantanen, Peripheral Disclosure, 74 PITT. L. REV. 1, 39-41 (2012) (defending patent disclosure requirements by noting that peripheral disclosure allows patents to disseminate their information in areas other than the patent document).

${ }^{43}$ Joseph P. Fishman, Creating Around Copyright, 128 HARV. L. REV. 1333, 1384 (2015).

${ }^{44}$ Joseph P. Fishman, The Copy Process, 91 N.Y.U. L. REV. 855, 856 (2016).
} 
For the purposes of our discussion, we can characterize intellectual property doctrine as a mechanism for redressing certain "failures of appropriability" common to innovative activity. In a perfectly competitive market, the appropriability landscape is flat in the following sense: all competitors producing a given product or service face the same production costs, and prices will be set to cover those costs-assuming there is sufficient consumer demand. ${ }^{45}$ Thus, in a perfectly competitive market, the portfolio of goods and services produced by the market is determined only by the way that consumer demand relates to production costs. Without intellectual property, however, potential innovators do not see such a flat appropriability landscape because freeriding competitors can set prices too low to cover the innovator's $R \& D$ investments. Unless first mover advantages or other non-market rewards are sufficient to cover R\&D investments, innovations inhabit troughs of under-compensation in the appropriability landscape. Even when consumer demand is sufficient to cover R\&D costs, innovators will be unable to appropriate sufficient returns to cover them.

Intellectual property doctrine is designed to fill in those troughs through limited grants of market exclusivity, avoiding both over and under-compensation to even out the landscape so that market production will reflect consumer demand. The intellectual property solution, however, has at least two important limitations, (i) intellectual property awards can over or under-compensate innovators for their R\&D investments, and (ii) intellectual property is concentrated in fighting only one sort of appropriability failure: freeriding by competitors.

Intellectual property doctrine reflects an assumption that "failures of appropriability" affect wide swaths of goods and services in roughly the same way. It is thus designed to be neutral-for the most part-across its areas of applicability. ${ }^{46}$ Doctrines such as patent law's "person having ordinary skill in the art," ${ }^{47}$ introduce some variability, but serve mostly as ways to (i) determine whether intellectual property exclusivity is necessary or (ii) tailor the protection's scope to the innovator's contribution. As a result, the exclusivity returns associated with intellectual property

\footnotetext{
${ }^{45}$ In the simplest model, price will be set at marginal cost. In the real world, production of goods and services also requires some fixed investments, which must be covered by revenues. These fixed investments ordinarily do not cause appropriability failures because they are roughly the same for all competitors.

${ }^{46}$ This is especially true of patent law, which applies nominally the same doctrinal rules to all technological arenas. Copyright recognizes more special cases, but nonetheless the basic rules governing scope and limitations apply to all types of "expression."

${ }^{47}$ USPTO, MANUAl of PATENT EXAmining PROCEDURE § 2141.03 (9th ed. 2018) (explaining "a hypothetical person who is presumed to have known the relevant art at the time of the invention. Factors that may be considered in determining the level of ordinary skill in the art may include: (1) 'type of problems encountered in the art;' (2) 'prior art solutions to those problems;' (3) 'rapidity with which innovations are made;' (4) 'sophistication of the technology; and' (5) "educational level of active workers in the field .... In a given case, every factor may not be present, and one or more factors may predominate."').
} 
awards are only roughly in line with $\mathrm{R} \& \mathrm{D}$ investments. Because tailoring intellectual property awards precisely to $\mathrm{R} \& \mathrm{D}$ investments would be impractical and prohibitively costly, intellectual property doctrine represents a balance between the costs and benefits of such tailoring. This means that while intellectual property fills in the large troughs created by freeriding, the appropriability landscape inevitably remains somewhat rough, scattered with hillocks of over-compensation and hollows of under-compensation. Market innovators respond to the combination of demand signals and appropriability. A given demand portfolio highlights a particular landscape of hillocks and hollows. Regulation shifts the demand portfolio, highlighting different parts of the landscape with different distributions of hillocks and hollows. If intellectual property doctrine is well-designed, however, the hillocks and hollows it creates are reasonably small and relatively uniform.

Another one of intellectual property doctrine's aims is to roughly equalize appropriability along different innovative paths so that market demand and innovator ingenuity-rather than rent-seeking-determine the innovations that the market induces. Exclusive rights in intellectual property are designed to mitigate a particular set of "failures of appropriability," namely freeriding by competitors. However, in some contexts, innovators also face the risk of freeriding by consumers. The most important such context is broadcast media. Consumers free ride when they can take advantage of an innovation without paying for it because practicalities make it difficult or impossible for producers to identify users and demand payment. ${ }^{48}$ Television and radio confronted just this problem, since it was essentially impossible to monitor and demand payment for consumption of content once it was broadcast into the ether. ${ }^{49}$ Even though copyright and patent rights apply to consumers in principle, intellectual property is often unenforceable against them..$^{50}$ Not only would intellectual property enforcement often be difficult and expensive, but lawsuits targeted at personal uses and noncommercial infringements have proven only mildly successful, while tremendously damaging for businesses' reputations. ${ }^{51}$ The market-based solution that developed to address this type of supplyside problem in the broadcast context was advertising-supported media. Advertisers were willing to pay in proportion to the crowd of "eyeballs"

\footnotetext{
${ }^{48}$ This problem obviously affects not only the ability to recoup upfront creative investments, but the ability to collect revenues for more mundane operating costs.

${ }^{49}$ See Harry P. Warner, Unfair Competition and the Protection of Radio and Television Programs I, 1950 WASH. U. L. Q. 297 (1950).

${ }^{50}$ See, e.g., John Tehranian, All Rights Reserved? Reassessing Copyright and Patent Enforcement in the Digital Age, 72 U. CIN. L. REV. 45, 59 (2003) ("However, even if the Dutch court rules against KaZaa, enforcement of its ruling will be difficult. Modern purveyors of piracy are either internationally dispersed individuals operating on a decentralized P2P system, such as Gnutella, or they are nimble shell corporations that can easily relocate their systems and operations to a venue with favorable laws.").

${ }^{51}$ See William T. Gallagher, Trademark and Copyright Enforcement in the Shadow of IP Law, 28 SANTA Clara COMPUTER \& High TECH. L.J. 453, 496 (2011).
} 
the broadcast attracted, thus providing an income stream that was roughly correlated with consumer demand for particular programming. ${ }^{52}$ In this sense, advertising income serves as a form of underwriting for creative investment, mitigating a failure of appropriability caused by consumer freeriding. ${ }^{53}$

\section{Barriers to Entry and Competition Law}

The market's portfolio of innovative activity might also be distorted by other sources of appropriability failures that are more contextual and less related to innovation per se. Barriers to entry are one such source of appropriability failure. Barriers to entry favor early entrants by imposing higher upfront costs on later market entrants. Here, we focus on natural barriers to entry, rather than those created by anticompetitive behavior, which we leave to antitrust law. ${ }^{54}$ One important mechanism for creating natural barriers to entry is the network effect, whereby a product or service's value to each consumer depends not only on its quality, but also on the number of other consumers using it..$^{55}$ Think, for example, of a telephone network, or, for a more current example, of a social media platform such as Facebook. The more users there are on the network, the more valuable the product is to each user and the harder it is for later entrants to offer attractive alternatives.

For our purposes, barriers to entry are significant because they are an additional source of appropriability failure. The prospect of benefitting from natural barriers to entry can create hills-or even mountains-in the appropriability landscape, making particular sorts of innovative activity overly attractive to suppliers. The need to compete with an incumbent who currently benefits from barriers to entry creates troughs in the appropriability landscape that make competitive follow-on innovation less

52 See Blaine Bassett, The Inevitable Television Revolution: The Technology Is Ready, The Business Is Lagging, and the Law Can Help, 29 SYRACUSE SCI. \& TECH. L. 1, 30 (2013).

${ }^{53}$ Today, advertising's importance as a mechanism for addressing consumer freeriding has substantially diminished since the emergence of cable and online content delivery mechanisms that can be metered. In the meantime, however, the advertising-based business model combined with data-intensive ad targeting, has taken on a new life that is relatively detached from its origins as a solution to consumer freeriding. See generally Katherine J. Strandburg, Free Fall: The Online Market's Consumer Preference Disconnect, 2013 U. CHI. LEGAL F. 95 (2013).

${ }^{54}$ There is an ongoing debate about the goals and proper role of antitrust law, which we do not attempt to engage here. See JONATHAN Galloway ET AL., MODERn InTEllectual PROPERTY LAW 20-21 (3d ed. 2010) (discussing the aims of competition law); see, e.g., Philip C. Kissam, Symposium: Antitrust Boycott Doctrine, 69 IOWA L. REV. 1165, 1170 (1984) (discussing two primary purposes of antitrust law, one of which is to "preserv[e] opportunities for small businesses"). We also take no position on the question of how antitrust law should respond (if at all) to natural barriers to entry.

${ }^{55}$ See Mark A. Lemley \& David McGowan, Legal Implications of Network Economic Effects, 86 CALIF. L. REV. 479, 483-84 (1998) (defining "network effect"). 
attractive, much like raising upfront costs or raising the quality bar. ${ }^{56}$ In some circumstances, antitrust law is needed to reduce barriers to entry. When that is the case, these appropriability distortions will be modified and hopefully reduced.

From the perspective of a prospective innovator looking out over the appropriability landscape, it is the combination of these effects that matters. While expected consumer demand is a prerequisite for marketinduced innovation, the attractiveness of a given innovation path depends on a variety of factors. Such factors include whether an innovator expects to be able to recoup his/her investments using intellectual property, whether she anticipates taking advantage of barriers to entry, and whether she needs to factor in the costs of overcoming such barriers. Appropriability expectations for a given innovative activity can exhibit offsetting effects. The innovator may be at a disadvantage with respect to later entrants because of freeriding, while at the same time benefitting from anticipated barriers to later entry, such as network effects. Appropriability failures can also be compounded if overprotective intellectual property laws combine with the benefits associated with barriers to entry.

Rather than offering insights on how best to design intellectual property law and competition law to deal with appropriability failures, our focus in this Essay is on the interaction between regulation and innovation. We therefore take those areas of doctrine as given and explain how regulation's realignment of demand combines with the appropriability landscape to change the market's portfolio of innovative activities.

\section{Regulation and Innovation: Effects of Re-Aligned Demand}

We break our consideration of the likely effects of regulation on innovation and the extent to which regulation is likely to "stifle" innovation into two parts. In Section IV.A, we consider the direct effects of regulation's re-alignment of demand signals. In Section IV.B we consider regulation's potential effects on innovation through its interactions with appropriability failures.

\section{A. Direct Effects of Re-Aligned Demand}

The goal of regulation is to realign the market's portfolio of demand along more socially desirable lines. Because the market's innovative activity is responsive to market demand, one obvious result of regulation is likely to be a shift in the market's portfolio of innovative activity. A welldesigned regulation-one that shifts perceived demand closer to social preferences and at a cost that does not outweigh the benefits of that re-

${ }^{56}$ See, e.g., J. H. Reichman, Of Green Tulips and Legal Kudzu: Repackaging Rights in Subpatentable Innovation, 53 VAND. L. REV. 1743, 1769 (2000) (explaining how patent law can raise the bar for follow-on innovators). 
alignment-is highly likely to reduce perceived demand for some sorts of innovative activity and increase demand for others. ${ }^{57}$

\section{Regulation and Effects on the Distribution of Innovation}

In a well-functioning market, these changes in demand would drive changes in the direction of innovative activities. Indeed, motivating innovation in socially promising directions is a primary purpose of various regulatory programs, including certain types of tax deductions and tax credits. $^{58}$ For example, CAFÉ regulations decrease demand for innovations in gas-guzzling vehicles while increasing demand for innovations in energy-efficient automotive technology. ${ }^{59}$ Regulations capping emissions from coal plants reduce effective demand for innovations relating to highemission plants, while increasing effective demand for low-emission technology.

These effects on the distribution of innovative activity are likely to create winners and losers. While losers may complain that the regulation "stifles" innovation, such intended shifts are not "stifling" in any socially meaningful sense. The mere fact that a regulation dampens some innovative activities is not evidence that it is "stifling" innovation-indeed, it may indicate that the regulation is working.

As the Porter Hypothesis suggests for environmental regulation, it is entirely possible that by shifting innovative activity to more socially beneficial paths, regulation may stimulate innovation and thus economic growth over the long term. ${ }^{60}$ As already mentioned, the Porter Hypothesis remains controversial but has received considerable empirical support. ${ }^{61}$ Indeed, its "weak" form, which simply argues that regulation can

${ }^{57}$ Suzanne Scotchmer, Cap-and-Trade, Emissions Taxes, and Innovation, 11 InNOVATION POL'Y \& ECON. 29, 49 (2011) (concluding that "[a]ny regulatory policy that imposes financial burdens for emitting carbon also creates an incentive to invest in carbon-reducing technologies").

${ }^{58}$ See Jacob Nussim \& Anat Sorek, Theorizing Tax Incentives for Innovation, 36 VA. TAX REV. 25, 34-35 (2017) (giving a brief background on the use of taxes to encourage innovation).

${ }^{59}$ Joseph M. Crabb \& Daniel K.N. Johnson, Fueling Innovation: The Impact of Oil Prices and CAFE Standards on Energy-Efficient Automotive Technology, 31 ENERGY J. 199 (2010).

${ }^{60}$ See Burak Sen, Mehdi Noori \& Omer Tatari, Will Corporate Average Fuel Economy (CAFE) Standard Help? Modeling CAFE's Impact on Market Share of Electric Vehicles, 109 ENERGY POL'Y 279, 279 (2017) (finding that " $[\mathrm{t}]$ his resulting improvement in vehicle fuel economy is likely to influence consumers' decisions regarding new vehicle purchases, while the stringent CAFE standards are also likely to affect manufacturers' production costs and benefits. In addition, the government provides various incentives to support the adoption of alternative fuel vehicles (AFVs), including electric vehicles (EVs), which in turn will likewise influences consumers' decisions regarding purchasing a new vehicle.").

${ }^{61}$ Michael Porter, America's Green Strategy, 264 SCI. AM. 168 (1991). The success of the hypothesis depends significantly on the context. For empirical support of the hypothesis, see, for example, Antoine Dechezleprêtre \& Misato Sato, The Impacts of Environmental Regulations on Competitiveness, 11 REV. ENVTL. ECON. \& POL'Y 183 (2017); Shunsuke Managi et. al., Environmental Regulations and Technological Change in the Offshore Oil and Gas Industry: Rethinking the Porter Hypothesis, 81 LAND ECON. 303 (2005); and Yana Rubashkina, Marzio Galeotti, \& Elena Verdolini, Environmental Regulation and Competitiveness: Empirical Evi- 
open up new innovation paths, is strongly supported. ${ }^{62}$ Gains in fuel efficiency motivated by the CAFÉ rules are one example of such regulationdriven innovation. ${ }^{63}$ The development of the electric car industry is another. Electric cars are becoming increasingly popular, even in the face of low gas prices, partly due to regulation at the federal level and in the nine states that have adopted zero-emission plans. ${ }^{64}$

When a regulation's expected impact on the social value of future innovation can be predicted and assessed, that impact should be considered in deciding whether and how to regulate. ${ }^{65}$ But innovation is path dependent, unpredictable, and cumulative ${ }^{66}$ so one might worry that realignments of demand that seem like a good idea now might turn out to be bad in the long run. Should one refrain from regulation out of fear of deterring innovations that appear to have low social value now, but would lead to unexpectedly high social value in the future?

Firstly, a regulation's potential for suppressing high social value innovation in the long run must always be weighed against the long-term social costs of the unregulated demand portfolio's misalignment with social value. Secondly, some of our current uncertainty about the ultimate social value of pursuing particular innovative paths arises from the risk of failure. As Liskow and Karpilov have argued, that risk itself is path dependent in a way that increases the benefit of regulation that realigns innovative activity with social preferences. ${ }^{67}$ Thirdly, if the argument is that innovation is truly unpredictable and serendipitous, so that its long-term social value cannot be usefully assessed as part of our evaluation of regulatory design, ${ }^{68}$ then the argument proves too much. Who, then, can say whether the unregulated or regulated demand portfolio will elicit the most socially beneficial innovation in the long run?

So far, we have focused on well-designed regulation. In regulation, as in many areas of life, however, there is the realistic chance that regulation will not achieve its intended goal. A regulatory process can fail in

dence on the Porter Hypothesis from European Manufacturing Sectors, 83 ENERGY POL'Y 288 (2015).

${ }^{62}$ See Ambec et al. supra note 17, at 9-10.

${ }^{63}$ See, e.g., Crabb \& Johnson, supra note 59.

${ }^{64}$ Farhad Manjoo, Trump Says Regulations Impede. Perhaps Not in the Electric Car Business, N.Y. TIMES (Mar. 22, 2017), https://www.nytimes.com/2017/03/22/technology/electric-carregulations-trump.html [https://perma.cc/EHZ8-BAHV].

${ }^{65}$ For many, the approach of choice is some version of cost-benefit analysis. $C f$. Exec. Order No. 12,866, 58 Fed. Reg. 51,735 (Oct. 4, 1993). Here, we remain intentionally agnostic as to the best approach to evaluating whether a particular regulation will realign demand signals in a socially beneficial way. The point is simply that the possible long-term social value of an innovative activity should be included in the evaluation of regulatory design to the extent it is possible to do so.

${ }^{66}$ This is what Liscow and Karpilow have termed "Innovation Snowballing." Liscow \& Karpilow, supra note 31 .

${ }^{67}$ Liscow \& Karpilow, supra note 31.

${ }^{68}$ One way to view this distinction is through the lens of "risk" versus "uncertainty." See FrANK H. KNIGHT, RISK, UNCERTAINTY AND PROFIT (1921). 
many ways: by being "captured" by improper influences,${ }^{69}$ by incorrectly identifying failures of perceived demand, by inaccurately assessing and predicting the costs and benefits of a given regulatory design, by not considering the best design, and more. Sometimes the benefits of even the best practical regulatory design for addressing a particular failure may be outweighed by its costs. Vulnerabilities in regulatory processes exist notwithstanding the strength of the underlying justification for regulation, and the choices of regulatory design have been a source of long scholarly debates in virtually all regulatory arenas.

Badly designed regulation could unintentionally shift demand signals in socially undesirable directions. If that happens, it might be sensible to speak of "stifling" innovation, even if the shift simply redirects innovative activity. While this is a real concern, the mere possibility of error cannot mean that demand signals should be unregulated, especially when these signals are significantly misaligned with social values.

\section{Reduction in Total Innovative Activity}

The contention that regulation will stifle innovation is most naturally understood to mean that regulation causes the total amount of innovative activity to decrease. Measuring, or even defining, the amount of innovation that is occurring, much less how any such amount of innovation is affected by regulation, is notoriously difficult, both conceptually and empirically. ${ }^{70}$ Nonetheless, for the sake of argument, we proceed under the presumption that some meaningful metric for the total amount of innovation can be established. We first consider whether and how well-designed regulation could decrease total innovation and then discuss how the potential for regulatory design error affects the picture.

A regulation that is well-designed to align the demand portfolio closer to actual individual and social preferences might result in less innovation overall by some metrics. The socially preferable demand portfolio, for example, might be less geared toward innovative activity. Against the backdrop of widespread belief that innovation is socially beneficial, this is an unlikely result of a well-designed regulation. However, innovation is not the only value we care about. It is possible for an unregulated demand portfolio to incentivize too much innovative activity at the ex-

\footnotetext{
${ }^{69}$ See, e.g., William W. Bratton \& Joseph A. McCahery, Regulatory Competition, Regulatory Capture, and Corporate Self Regulation, 73 N.C. L. REV. 1861 (1995).

${ }^{70}$ Scholarly attempts to empirically test the relationship between regulation and innovation include, Crabb \& Johnson, supra note 59; Avi Goldfarb \& Catherine Tucker, Privacy and Innovation, 12 INNOVATION POL'Y \& ECON. 65, 84-86 (2012); Nathan Goldschlag \& Alex Tabarrok, Is Regulation to Blame for the Decline in American Entrepreneurship? 33 ECON. POL'Y 5 (2018); Managi et. al., supra note 61 . None to date has conclusively showed that regulation has generated innovation-stifling effects.
} 
pense of other social values. ${ }^{71}$ In these situations, well-designed regulations would reduce the total amount of innovation. As such, it may be unreasonable to characterize the regulation as stifling.

Another global argument for why regulation will stifle innovation is that regulatory compliance and transaction costs will reduce the resources available for innovation. ${ }^{72}$ Regulatory compliance undoubtedly creates transaction costs, which in general are wasteful and can decrease the total resources available in society. ${ }^{73}$ Well-designed regulation could minimize such costs and take them into account in deciding whether the regulatory effort is economically justifiable. But, in any event, compliance costs, whether or not minimized through regulatory design, will not necessarily reduce investments in innovative activity even in the regulated sector, much less overall. Reduced innovative activity in the regulated sector is likely to occur only when compliance costs are (i) imposed on the regulated sector but not spread throughout society, and (ii) targeted so as to make innovation in that sector less attractive to investors.

Whether compliance costs are borne by the regulated sector is a matter of regulatory design. Compliance costs commonly are borne by regulated entities ${ }^{74}$-sometimes for convenience and sometimes as a regulatory tool-but can, in principle, be spread broadly throughout society using various mechanisms such as tax rebates. Some compliance costs, such as the costs of paperwork, training, monitoring, and reporting, are borne by regulated entities, but do not rise in proportion to their innovative activity. General increases in the cost of doing business might, but need not, reduce the budget for innovative activity. To the extent that a particular innovative activity remains a good business proposition, investors will support it.

Even when compliance costs make innovative activity in a regulated sector less attractive, there is no particular reason to anticipate that there will be less innovation overall, since investments can be shifted from one sector to another and net innovation will remain the same. Oftentimes, that is the intended purpose of the regulation. Regulation can, of course, also motivate innovations aimed at reducing compliance and transaction

\footnotetext{
${ }^{71}$ The question of whether "overall" innovation is reduced depends, of course, on the metric one uses. One possible sense in which well-designed regulation might reduce overall innovation might be to shift demand away from relatively "easy" (and thus immediately productive) innovative paths with low-hanging fruit toward more socially valuable, but more difficult and thus less productive in the short term, paths.

${ }^{72}$ See, e.g., G. William Schwert \& Paul J. Seguin, Securities Transaction Taxes: An Overview of Costs, Benefits and Unresolved Questions, 49 FIN. ANALYsTs J. 27, 32 (1993).

${ }^{73}$ See Frank A.G. den Butter, Marc de Graaf \& André Nijsen, The Transaction Costs Perspective on Costs and Benefits of Government Regulation: Extending the Standard Cost Model 2 (Tinbergen Institute, Discussion Paper No. 09-013/3, 2009), available at https://papers.ssrn.com/sol3/papers.cfm? abstract_id=1345789.

${ }^{74}$ See Wim Marneffe \& Lode Vereeck, The Meaning of Regulatory Costs, 32 EUR. J.L. \& ECON. 341,350 (2011).
} 
costs. ${ }^{75}$ Thus, only a subset of compliance costs are likely to depress innovative activity in a regulated sector: those that are (i) imposed on innovators in proportion to their innovative activity, (ii) unavoidable through compliance-related innovation, and (iii) not recoupable via first-mover advantages or intellectual property. With the exception of pharmaceutical regulation, ${ }^{76}$ intellectual property doctrine is not generally designed with compliance costs in mind. As a result, regulations that create these sorts of compliance cost might-on average and depending on how large the costs are-depress overall innovative activity in a regulated sector.

In sum, the above analysis, though highly stylized, rebuts the sweeping contention that "regulation" will "stifle" innovation either through its direct effects on market demand signals or by imposing compliance costs. A regulation's likely effects on innovation depend on its details and overall stifling seems like a fairly peripheral concern. Claims about regulationinduced stifling also fail to consider the stifling effects of non-regulation in a market that is infested with various failures. Indeed, generalized handwringing about regulation's innovation-stifling effects shifts attention away from more specific and important questions regarding regulatory design and the re-direction of innovative activity towards more socially desirable outcomes.

\section{The Interplay Between "Failures of Appropriability" and \\ Realignment of Demand}

We now turn to the possible interplay between regulation's realignment of demand and "failures of appropriability." As we have emphasized, the market's portfolio of innovative activity reflects the combination of demand signals with appropriability expectations. By realigning demand signals, regulation necessarily shifts the way that demand interacts with appropriability to induce the portfolio of innovation that the market ultimately produces. In essence, the regulated and unregulated demand portfolios draw innovators' attention to different parts of the appropriability landscape, which can either (i) increase or diminish the regulation's expected social benefits or (ii) leave them unchanged. At the extreme, even a regulation that realigns demand signals perfectly with social preferences could combine with an unfavorable appropriability terrain to induce a portfolio of market innovation that is worse from a social perspective.

\footnotetext{
${ }^{75}$ Winston Harrington, Richard D. Morgenstern, \& Peter Nelson, On the Accuracy of Regulatory Cost Estimates, 19 J. POL'Y ANALYSIS \& MGMT. 297, 309-10 (2000).

${ }^{76}$ The influence of pharmaceutical regulatory costs on patent law is both explicit, see, for example, Drug Price Competition and Patent Term Restoration Act of 1984 (Hatch-Waxman Act) Pub. L. No. 98-417, 98 Stat. 1585 (1984) (codified as amended in title 21 of the U.S.C.) and, arguably, implicit in the way that various general doctrines are interpreted in that arena.
} 
One could argue that regulatory design should routinely try to take specific account of such variations in the appropriability terrain. This, however, seems like a fools' errand in the run-of-the-mill case. When variations in the appropriability landscape are small and distributed reasonably uniformly, the parts of the appropriability landscape highlighted by regulated and unregulated demand portfolios are likely to be similarly over and under-compensatory. As discussed above, we ordinarily rely on intellectual property doctrine to smooth out the appropriability landscape in just this way. ${ }^{77}$ Because intellectual property doctrine has developed to balance the costs of intellectual property protection with the benefits of smoothing out the appropriability terrain, intellectual property law seems to be an appropriate place to focus general debates about whether closer tailoring is appropriate. As a result, regulatory design, in theory and in practice, often proceeds without paying much attention to "failures of appropriability."

Moreover, there is ordinarily no reason to expect that regulation will change the market's overall balance of over and under-compensation in any systematic or significant way. In most contexts, intellectual property will be roughly equally effective (or flawed) for both regulated and unregulated demand portfolios. This is especially likely when regulated and unregulated innovation are of the same technological ilk, as is often the case. Consider, for example, regulations requiring child-resistant packaging for medications and household chemicals. Those regulations surely shift demand for innovation away from easy-opening packaging and toward child-resistant packaging. ${ }^{78}$ Similarly, environmental regulation shifts demand away from gas guzzlers and toward fuel-efficient vehicles. ${ }^{79}$ Presumptively, easy-opening and child-resistant packaging innovations

\footnotetext{
${ }^{77}$ Competition law arguably has a similar role with respect to barriers to entry, though this is an area of contention. See, e.g., Jay Modrall, A Closer Look at Competition Law and Data, COMPETITION L. INT'L 5-6 (2017) (“According to the Franco/German Study, in markets for which access to a large volume or variety of data is important, the need for such data may result in entry barriers when new entrants are unable either to collect or buy access to the same kind of data. ... On the other hand, the Franco/German Study notes (in a footnote) that big data can also reduce entry barriers, for instance when data can be used by new entrants to identify and satisfy consumer needs."); see also, Daniel L. Rubinfeld \& Michal S. Gal, Access Barriers to Big Data, 59 ARIZ. L. REV. 339, 342 (2017); David L. White, Shaping Antitrust Enforcement: Greater Emphasis on Barriers to Entry, 1989 B.Y.U. L. REV. 842, 850 (1989) ("[E]ntry barriers are only one of many factors accepted by the courts in demonstration of attempted monopolization. ... [A]ntitrust principles are most sensibly constructed when promoting conditions favorable to easy entry and exit"). To the extent that competition law succeeds in removing barriers to entry, this point also applies to it.

${ }^{78}$ See, e.g., Vikas Pareek \& Alok Khunteta, Pharmaceutical Packaging: Current Trends and Future, 6 INT'L J. OF PHARMACY AND PHARMACEUTICAL SCI. 480, 482 (2014) (explaining certain innovations in child-resistant packaging, which is an "essential criterion" for the success of potent drugs).

${ }^{79}$ See Rebecca Bellan, The Grim State of Electric Vehicle Adoption in the U.S., CiTYLAB (Oct. 15, 2018), https://www.citylab.com/transportation/2018/10/where-americas-charge-towardselectric-vehicles-stands-today/572857 [https://perma.cc/WLK4-DMQ8] (explaining how California's relatively aggressive environmental regulations have made electric vehicle adoption the highest out of any state).
} 
are similarly protectable with intellectual property, as are gas guzzling and fuel-efficient innovations. Any differences between the relevant appropriability landscapes are unlikely to be any more severe or systematic than the differences in appropriability that we routinely tolerate under intellectual property doctrine. Another example is R\&D tax credits, ${ }^{80}$ which stimulate innovative activity by reducing its cost, but do not affect the appropriability of returns from successful $\mathrm{R} \& \mathrm{D}$, which is determined by standard intellectual property doctrine. In these contexts, it thus makes perfect sense for regulators to leave appropriability concerns to intellectual property and, to some extent, competition law. In fact, that is the standard practice.

In some regulatory contexts, however, demand shifts are correlated significantly with appropriability failures, undercutting the separability assumption. Such correlations can have either positive (in the sense that aligning demand signals with social value systematically mitigates appropriability failure) or negative (in the sense that aligning demand signals with social value systematically exacerbates appropriability failure) effects on the overall social value of market innovation.

Traditional network effects, such as those associated with telephone networks, simultaneously create value for consumers and barriers to entry that deter competitive or follow-on innovation and can lock consumers into less preferable technologies. ${ }^{81}$ One way to mitigate appropriability failures in such contexts is to break up networks. However, breaking up networks would simultaneously reduce the networks' value to consumers. When there is this sort of negative correlation, regulatory design should account for tradeoffs between appropriability and demand. In fact, regulatory design in arenas characterized by strong network effects commonly attempts to take these tradeoffs into account explicitly, preserving network benefits for consumers as much as possible, while decreasing barriers to competitive and follow-on innovation. ${ }^{82}$ Regulatory

\footnotetext{
${ }^{80}$ See Nicholas Bloom, Rachel Griffith \& John van Reenen, Do R\&D Tax Credits Work? Evidence from a Panel of Countries 1979-1997, 85 J. PUB. ECON. 1 (2008).

81 See, e.g., Sean Howell, Big Data and Monopolization 4 (2018), available at https://papers.ssrn.com/sol3/papers.cfm?abstract_id=3123976 ("[D]ata-driven markets tend to feature strong network effects and economies of scale, which create barriers to entry that other firms may have a hard time overcoming."); Jens Prufer \& Christoph Schottmuller, Competing $\begin{array}{llllll}\text { with Big Data } & 2, & 15 & \text { (2017) available at }\end{array}$ https://papers.ssrn.com/sol3/papers.cfm?abstract_id=2918726; Joseph Farrell, Coordination and Lock-In: Competition with Switching Costs and Network Effects, in 3 HANDBOOK INDUS. ORG. 1967, 2034 (2007) (“[E]arly choices are powerful, able either to help coordination or to wield disproportionate influence. Thus any early lead in adoptions (whether strategic or accidental) will tend to expand rather than to dissipate. Network markets are 'tippy': early instability and later lock-in.").

${ }^{82}$ See, e.g., Nicholas Economides, Antitrust Issues in Network Industries, in THE REFORM OF EC COMPETITION LAW 343, 367 (Ioannis Kokkoris \& Ioannis Lianos eds., 2009) (explaining the U.S. government and European regulators' attempts to maintain competitiveness in the telecommunications industry without destroying the positive externalities from network effects).
} 
approaches of this sort include technological standards, interconnection requirements, and so forth.

Correlation between demand and appropriability can also produce socially desirable side effects. For example, an environmental regulation aimed at encouraging the use of alternative energy sources might increase market demand for solar panels and decrease demand for electricity produced by coal plants. Though the direct effects of this shift in demand may have been the regulation's only intended effect, its ultimate impact would also reflect systematic differences in the extent to which solar panel innovation and coal plant innovation are susceptible to appropriability failures. Thus, if supplying electricity over power lines from power plants creates barriers to entry, but supplying electricity using solar panels does not, electricity markets might become less infected with appropriability failures once the regulation is in place.

Another example from the broadcast media context discussed earlier illustrates how correlations between demand and appropriability can produce either positive or negative side effects, depending on contextual specifics and regulatory details. As discussed above, the advertisingsupported business model was created at least partly in response to gaps in intellectual property law's response to customer free-rider problems. While this business model addresses these free-rider problems, it simultaneously creates misalignment between market demand for programming content and social preferences. Suppose that a regulation is designed to realign broadcast programming content more closely with individual and social preferences by creating barriers to advertiser influence on content. The realigned demand portfolio will presumably be less favorable to advertisers, thus offering smaller returns on investment in content creation. The market's ultimate production of broadcast programming will reflect both the intended demand realignment and this appropriability side effect. The overall result of the regulation could be either socially salutary or socially detrimental. If the unregulated advertising-based business model tends to overcompensate content creators for their upfront costs, the regulation might simultaneously improve the market's satisfaction of consumer and social preferences and mitigate appropriability failures-a win-win result. But if the regulation reduces advertising revenue so much that investments in creating socially desirable content would be under-compensated, the result would be an overall social loss. The result might also be somewhere in between, with the overall evaluation of the regulation dependent on whether the advantages of better alignment with social preferences outweigh the loss of investment in creating socially valuable content. The crucial point is that when correlations between demand and appropriability materialize, one cannot presume separability.

It is also possible, as discussed above, that regulatory compliance costs are correlated with the intensity of innovative activity. When that is 
the case, regulation effectively raises the upfront cost of innovation, potentially upsetting intellectual property's effectiveness in smoothing out the appropriability landscape. Pharmaceutical regulation arguably imposes this sort of compliance costs. ${ }^{83}$ The studies required to meet FDA safety and efficacy standards create high compliance costs that are (i) tacked on to the upfront costs of drug innovation and (ii) not accounted for by intellectual property doctrine.$^{84}$ In response to this concern, Congress enacted a complex array of regulatory "fixes," including, a period of "data exclusivity." ${ }^{85}$ During the data exclusivity period, innovators have an exclusive right to rely on the safety and efficacy data they have submitted to the FDA, preventing generic companies from freeriding on it. ${ }^{86}$ Pharmaceutical regulation is probably unusual in having such large innovatorspecific compliance costs and there are debates about whether patent exclusivity truly fails to cover pharmaceutical companies' investments. ${ }^{87}$ Again, this discussion is simply to illustrate the kinds of situations in which regulatory design and evaluation should take account of appropriability effects.

\section{Conclusion}

The market's portfolio of innovative activity reflects suppliers' perceptions of market demand mixed with their expectations of appropriability. Regulation's traditional goal is to bring market demand into better alignment with individual and social preferences and values, while intellectual property law (and, at times, competition law) aims to bring suppliers' incentives into line with those preferences by smoothing out the appropriability landscape. In many contexts, these tasks are mostly separable. Regulatory design need not pay much attention to appropriability, while intellectual property doctrine assumes that market demand correctly reflects consumer preferences.

\footnotetext{
${ }^{83}$ See Ron A. Bouchard et al., The Pas De Deux of Pharmaceutical Regulation and Innovation: Who's Leading Whom?, 24 CALIF. L. REV. 1461, 1461 (2009) (arguing that "recent regulatory efforts designed to encourage the development of new and innovative drugs through the provision of strong patent and "linkage" rights, which legally tie drug patenting and drug approval, have in fact had the opposite effect."); see also Lacy G. Thomas, Regulation and Firm Size: FDA Impacts on Innovation, 21 RAND J. ECON. 497 (1990).

${ }^{84}$ See Thomas, supra note 83, at 501 (finding that FDA enforcement of premarket testing significantly hurt both firms producing generic or imitative products and small firms, whereas large firms had the resources to work with the "super-experts" who would conduct the required studies by the FDA).

${ }^{85}$ See C. Scott Hemphill \& Mark A. Lemley, Earning Exclusivity: Generic Drug Incentives and the Hatch-Waxman Act, 77 ANTITRUST L.J. 947, 947 (2011).

${ }^{86} I d$.

${ }^{87}$ See Maxwell R. Morgan, Regulation of Innovation Under Follow-On Biologics Legislation: FDA Exclusivity as an Efficient Incentive Mechanism, 11 COLUM. SCI. \& TECH. L. REV. 93, 97 (2010) ("There is an ongoing debate as to whether such FDA exclusivity is a necessary mechanism to prevent erosion of incentives.").
} 
As our analysis points out, however, this implicit assumption of separability is not always valid. Under some circumstances, correlations between preferences and appropriability failures demand attention to appropriability concerns as part of the regulatory design process. Viewing regulatory design and innovation policy through the prism of perceived demand and appropriability failures is not only essential in making the current oversimplified regulation-innovation debate more nuanced, but also offers a useful and comprehensive theory to evaluate the impact of regulation on innovation in broader, yet more contextual, terms. 